\title{
The complexity of p53 modulation: emerging patterns from divergent signals
}

\author{
Amato J. Giaccia ${ }^{1}$ and Michael B. Kastan ${ }^{2,3}$ \\ ${ }^{1}$ M ayer Cancer Biology Research Laboratory, Department of Radiation Oncology, Stanford University, Stanford, California \\ 94305-5468 USA; ²Department of Hematology-Oncology, St. Jude Children's Research Hospital, \\ Memphis, Tennessee 38105 USA
}

Functional inactivation of p53 by gene mutation and deletion, protein degradation, or viral oncogene binding renders a mammalian cell susceptible to oncogenic stimuli and environmental insults that promote growth deregulation and malignant progression. Although a variety of mechanisms have been proposed for how p53 protects cells against neoplastic transformation, it is becoming clear that p53 integrates signals from the cell's internal and external environment to respond to inappropriate growth promoting or growth inhibiting conditions (for review, see Gottleib and Oren 1995; Ko and Prives 1996; Levine 1997). This "sensor" function of p53 makes it unusual in the tumor suppressor gene family. The list of stimuli that alter p53 activity is increasing and our understanding of the signal transduction pathways used to signal to p53 are starting to become elucidated.

The predominant regulation of p53 occurs at the protein level. Mutations in p53 that affect its conformation typically increase its half-life, in part by inhibiting degradation by the ubiquitin complex (Maki et al. 1996; Haupt et al. 1997; Kubbutat et al. 1997; Midgley and Lane 1997), and the majority of human tumor mutations decrease the sequence-specific DNA binding and transcriptional activity of p53 protein (Cho et al. 1994). In unstressed cells, p53 appears to be present at low levels and exists in a latent, inactive form that requires modification to become active. The types of modification that p53 is subjected to seem to be stress-, species- and celltype-specific. Levels and/or activity of p53 increase in response to DNA damaging agents (Maltzman and Czyzyk 1984; Kastan et al. 1991; Nelson and Kastan 1994), decreased oxygen (Graeber et al. 1994), oncogenic stimuli (Debbas and White 1993; Lowe and Ruley 1993; Hermeking and Eick 1994; Wanger et al. 1994; Serrano et al. 1997), cell adhesion (Nigro et al. 1997), altered ribonucleotide pools (Linke et al. 1996), and redox stress (Hainaut and Milner 1993a; Hupp et al. 1993). Although all of these stresses signal the activation of p53 protein, unique pathways appear to be utilized by the different stresses.

${ }^{3}$ Corresponding author.

E-MAIL Michael.Kastan@stjude.org FAX (901) 495-3966.
Is p53 protein accumulation needed for p53 activation or are modifications necessary for p53 activation separable from the modifications required for p53 protein accumulation? Both the modifiers and the types of modification will be important to sort out to understand the relationship between accumulation and activation. Although the two appear to be separable (Chernov et al. 1998; Hupp et al. 1995), it is possible that both are essential for full tumor suppressor function.

The importance of p53 and modifications that affect its functions are not limited to malignant disease. The activity of p53 can increase in normal tissues when undergoing pathophysiological changes that result in oxidative or redox stress, such as ischemia and reperfusion injury of the brain, heart, and other tissues. Thus both oxidative stress generated by hydrogen peroxide, as well as reducing stresses generated by the lack of oxygen, appear to be potent stimulators of p53 activity. In addition, the link between p53 function and the modulation of angi ogenesis further implicates p53 pathways in the processes of wound healing (Antoniades et al. 1994) and ischemic injury responses (Banasiak and Haddad 1998). At present little is known about the pathways that control p53 activity in response to ischemia and reperfusion in normal tissues, and this area should be fertile ground for research in future years. In this review, we discuss what is known about how various stressors signal to p53 and the various mechanisms utilized to modulate p53 activity. Because of the focus on signal ing to p53, we will not attempt to discuss the "downstream" physiologic effects of p53 activation such as cell-cycle perturbations or cell death.

\section{General themes for modulating p53 activity}

Because p53 is such a critical cellular protein, it is not surprising that multiple mechanisms have evolved to regulate its activity. This myriad of modulatory mechanisms probably exists both to tightly and rapidly control the activities of $\mathrm{p} 53$ and to provide al ternative regulatory mechanisms for different cell types and different physiologic stimuli. In all of the discussions to follow of mechanisms used to modulate p53 function, several caveats need to be maintained. First, there will almost cer- 
tainly be cell type-specific differences in the mechanisms used to achieve certain end points. In addition, genetic differences in comparable cell types (e.g., oncogenic changes) could alter p53 signaling pathways. For example, a certain cytotoxic stimulus may use two different kinases in two different cell types to achieve the same post-translational modification or two different mechanisms may be used to achieve the same functional endpoint. In addition, two different stimuli may use two different kinases to achieve a particular post-translational modification. This is evidenced by the apparent use of two different kinases to phosphorylate serine 15 after ionizing radiation (IR) versus ultraviolet radiation (UV). Second, there may be different mechanisms utilized to regulate p53 function at different stages in the cell cycle. This may depend in part on cell cycle-dependent differences in expression or activity of certain modulatory proteins. Finally, for most of the p53 regulatory mechanisms discussed below, it is not clear what fraction of total cellular p53 contains the modification or is bound nor what fraction must be so modified to achieve a particular functional endpoint.

\section{Transcriptional or translational control}

There are few examples of situations in which p53 activity is controlled by altering the level of p53 mRNA. This observation is consistent with the need to typically modulate p53 function in an extremely rapid manner in most physiologic situations, and with the more efficient regulation and "fine-tuning" that can be done by modulating the protein product itself. In addition, it might also be disadvantageous to regulate p53 at the transcriptional level after damaging the DN A template. However, one setting in which p53 appears to be regulated at the level of mRNA expression is during the development of certain tissues, with spermatogenesis being the clearest example (Schwartz et al. 1993). It is al so noted that amplification of p53 genes, whether wild-type or mutant, and consequent overexpression of p53 mRNA has not been reported in human tumors.

Although levels of p53 mRN A do not change detectably in response to physiologic stimuli such as DNA damage, the levels of p53 protein increase rapidly (Kastan et al. 1991). The half-life of p53 protein increases measurably after DNA damage (Maltzman and Czyzyk 1984; Price and Calderwood 1993; Maki and Howley 1997), but it appears that enhanced translation of p53 mRNA also contributes to this induction. Protein synthesis inhibitors block the increase in p53 protein after DNA damage (Kastan et al. 1991) and both the $5^{\prime}$ and 3'-untranslated regions (UTRs) of p53 mRN A have been impl icated in regulating p53 protein levels (M osner et al. 1995; Fu and Benchimol 1997). In particular, Benchimol and colleagues utilized reporter constructs containing the $3^{\prime}$ UTR of p53 to conclude that IR increased p53 mRNA translation via this regulatory region ( $\mathrm{Fu}$ and Benchimol 1997). The rel ative contributions of enhanced translation versus increased half-life to DNA damageinduced increases in p53 protein levels remain to be clarified. It will not be surprising if the relative importance of these two processes varies in different cell types and with different stimuli.

\section{Alterations in p53 protein half-life}

p53 is a short-lived nuclear protein with a half-life of 5-20 min in most cell types studied. Following exposure to DNA damage, the half-life of p53 protein increases by severalfold ( $M$ altzman and Czyzyk 1984; Price and Calderwood 1993; Maki and Howley 1997). Recent studies have implicated the $\mathrm{Mdm} 2$ protein as a major intracellular regulator of ubi quitin-mediated degradation of p53 protein (Haupt et al. 1997; Honda et al. 1997; Kubbutat et al. 1997; Midgley and Lane 1997). It had been known for some time that the $\mathrm{M} \mathrm{dm} 2$ protein could inhibit p53 function by binding to and inhibiting transactivation by p53 (Momand et al. 1992; Oliner et al. 1993; Thut et al . 1997), but these recent studies demonstrated that $\mathrm{Mdm} 2$ binding also targets p53 for rapid proteosomal degradation. If $\mathrm{Mdm} 2$ fails to bind to $\mathrm{p} 53$, the intracellular levels of p53 protein increase, thus potentially contributing to the initiation of p53-dependent processes such as cell cycle arrest or apoptosis. The physiologic significance of this mechanism of p53 regulation has subsequently been supported by the observations that activation of p53 by either DNA damage (Shieh et al. 1997) or by oncogenes via p19ARF (de Stanchina et al. 1998; Zindy et al. 1998) are both associated with decreased binding of $\mathrm{Mdm} 2$ protein to p53 (Shieh et al. 1997; Kamijo et al. 1998; Pomerantz et al. 1998; Zhang et al. 1998). Other proteins also appear to target p53 stability as a mechanism of regulation. For example, it has recently been suggested that hypoxia increases p53 protein level s via induction of HIF- $1 \alpha$, which can bind to and stabilize p53 (An et al. 1998). Conversely, E6 protein from oncogenic human papillomaviruses decreases intracellular levels of p53 protein by enhancing its ubiquitin-mediated degradation (Scheffner et al. 1990; Werness et al. 1990).

\section{Alterations in p53 functional activity}

Changes in the levels of p53 cannot be the whole story in the regulation of p53 function. Both post-translational modifications and alterations in p53-binding proteins also appear to be major contri butors to the modulation of p53 activity. This was apparent initially from observations that, whereas recombinant p53 produced in bacteria bound poorly to DNA, sequence-specific DNA binding could be markedly enhanced by either carboxy-terminal phosphorylation or incubation with a carboxyterminal binding anti-p53 antibody (Hupp et al. 1993). Such studies implicated the carboxy-terminal domain of p53 as a regulatory region of the protein and subsequent studies have supported this concept (Hupp et al. 1995; Jayaraman and Prives 1995; Lee et al. 1995; Selivanova et al. 1997). Other characterized functional domains of p53 include sequences required for transactivation in the amino terminus, sequences required for specific DNA 
binding in the central portion of the protein, and sequences involved in ol igomerization in the carboxyl tail (Fig. 1). In addition, a proline-rich region exists between the amino-terminal transactivation domain and the central DN A-binding domain, which has been implicated in both p53-mediated growth arrest (Walker and Levine 1996) and apoptosis (Venot et al. 1998). Although the mechanisms remain to be elucidated, recent work has suggested that it cooperates with the carboxy-terminal domain in negatively regulating p53 function and maintaining p53 in a latent, low-affinity DNA-binding conformation (Muller-Tiemann et al. 1998).

The existence of these various regions of p53 that can modulate its activity sets up a situation in which a primary p53 regulatory mechanism could be by specific post-translational modifications of one or more of these domains, or modulation of proteins that bind to these domains. In fact, the scenario that is developing from recent studies is that a series of post-translational modifications occurs in p53 that can affect its levels, its function, its homo- and hetero-oligomerization, and its DNA-binding capabilities. Increasing the complexity of such scenarios is the likelihood that some of these posttranslational modifications in turn affect p53 functions

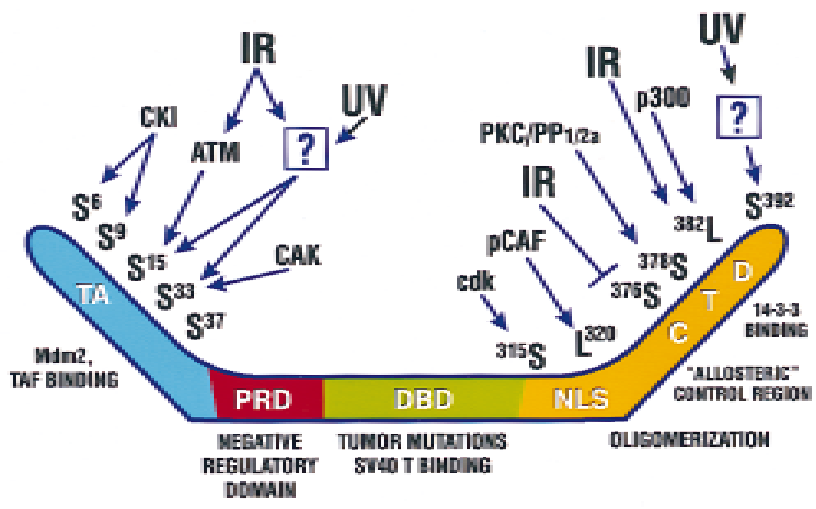

Figure 1. Schematic representation of p53 protein domains and post-translational modifications. p53 is a 393-amino acid protein with major domains characterized as transcriptional activation (TA), proline-rich domain (PRD), DNA-binding domain (DBD), nuclear localization signal (NLS), and carboxy-terminal domain (CTD). The TA is al so the region where $M \mathrm{dm} 2$ and TAF [TATA-binding protein (TBP)-associated factor] bind. PRD may be a negative regulatory domain. The $D B D$ is the site of the vast majority of tumor mutations and is the area where SV 40 Iarge T antigen binds. The CTD is considered the region of major allosteric regulation of p53 function and contains the sequences necessary for dimerization and tetramerization. CKI phosphorylates serines 6 and 9 in vitro. ATM and DN A-PK phosphorylate serine 15 in vitro and IR activates ATM kinase activity and ATM-deficient cells fail to phosphorylate this site optimally. CAK phosphorylates serine 33 in vitro and IR induces serine 33 phosphorylation. Cdk phosphorylates serine 315 in vitro. PKC phosphorylates and phosphatases 1 and 2a dephosphorylate serine 378 in vitro. pCAF acetylates Iysine 320 and p300 acetylates Iysine 382 in vitro. IR induces lysine 382 acetylation and serine 376 dephosphorylation. UV induces phosphorylation of serines 15, 33, and 392. by al tering its abilities to bind to other proteins. It is easy to see how these kinds of complex interactions could result in rapid and tight regulation of p53 protein.

In general, we still have a primitive understanding of the functional ramifications of any one of these posttranslational modifications and a discussion of these preliminary insights is beyond the scope of this article. However, it should be noted that elucidation of the functional role(s) for any given modification is difficult. First, a series of modifications may work in concert to achieve a particular functional endpoint and elimination of any one modification may have only a modest effect on that function. Second, the typical approach to analyzing the effects of a post-translational modification is to mutate that site in a recombinant cDN A vector and evaluate it for activity following transfection into a target cell. However, if the influence of a particular modification is modest and quantitative, it's importance may be obscured by overexpression of such a recombinant protein.

Post-translational modifications. I. Phosphorylation p53 is phosphorylated on numerous serines in both the amino- and carboxy-terminal domains, whereas the central core domain remains apparently free of post-translational modifications (Fig. 1). A number of kinases have been implicated in phosphorylation of p53 in vitro (Hupp and Lane 1994), including casein kinase I (serines 6 and 9; Milne et al. 1992), DN A-PK (serines 15 and 37; LeesMiller et al. 1990; Shieh et al. 1997), ATM and ATR (serine 15; Banin et al. 1998; Canman et al. 1998), CDKactivating kinase (CAK) (serine 33; Ko et al. 1997), cdk2 and cdc2 (serine 315; Bischoff et al. 1990; Price et al. 1995), protein kinase C (serine 378; Baudier et al. 1992), and casein kinase II (serine 392; Hall et al. 1996). [N ote: The residue numbers reflect the human p53 protein sequence.] These modifications likely represent the balances between phosphorylation and phosphatase events. Supporting such a concept was the observation that activation of latent recombinant p53 by protein kinase $C$ was reversi ble by treatment with protein phosphatases 1 or 2a (Takenaka et al. 1995). Many of these sites are al so phosphorylated in vivo, but which sites are modified in the basal state and which are altered in response to specific physiologic stimuli is only now beginning to be addressed. For example, IR appears to result in both de novo phosphorylation of serine 15 (Shieh et al. 1997; Siliciano et al. 1997) and dephosphorylation of serine 376 (Waterman et al. 1998).

Post-translational modifications. II. Acetylation Sequence-specific DNA binding is only one component of the ability of p53 to function as a transcription activator. p53 must also be able to interact with the transcriptional machinery to influence transcription of its target genes. In addition to interacting with components of TAF ( $\mathrm{Lu}$ and Levine 1995; Thut et al. 1995), members of the histone acetylase family, p300/CBP, have recently been shown to bind to p53 and enhance p53-mediated transcription (Avantaggiati et al. 1997; Gu et al. 1997; Lill et al. 1997a; Scolnick et al. 1997). The concept that this 
binding of p300/CBP to p53 was of functional importance was consistent with the previous observations that adenovirus E1A and SV40 large $T$ antigen both bind to members of the p300/CBP family (Eckner et al. 1994, 1996; Lill et al. 1997b) and both disrupt p53 functions (Steegenga et al. 1996). However, the binding of p300/CBP to p53 in the absence of these viral oncoproteins suggested a more direct mechanism of action and Gu and Roeder subsequently demonstrated that p300 can directly acetylate p53 in the regulatory region of its carboxy-terminal domain and that this acetylation activates the latent sequence-specific DNAbinding activity of p53 (Gu and Roeder 1997). Sakaguchi et al . (1998) then recently demonstrated that the acetyltransferases p300 and PCAF acetylate p53 in vitro at lysines 382 and 320, respectively, that these acetylation events enhance sequence-specific binding of p53, and that Iysine 382 becomes acetylated in response to DNA damage in cells. Furthermore, recombinant p53 protein that was phosphorylated previously by DNA-PK appeared to be a better substrate for the acetyltransferases than unphosphorylated p53. This latter observation suggests that a series of post-translational modifications may work interdependently, both in terms of their occurrence and their functional consequences (Fig. 2).

Redox modulation The relationship between p53 and intracellular redox parameters is probably quite complex, interacting at all levels of p53 induction and function. Reactive oxygen species are likely to be a signal that induces p53 and, in turn, the redox state of p53 appears to strongly influence its DN A binding and transcriptional activation function. For example, oxidized p53 loses its sequence-specific DN A-binding capabilities (Hainaut and M ilner 1993a), and dival ent metal cations, whose binding to p53 is dependent on the reduced state of certain cysteine residues, are critical for p53 function (Hainaut and Milner 1993b; Delphin et al. 1994; Ver- haegh et al. 1997). Furthermore, nitric oxide and thioredoxin reductase have recently been shown to affect p53 conformation and/or transcriptional activity (Calmels et al. 1997; Pearson and Merrill 1998). The demonstration that the redox/repair protein, Ref-1, activates the DNAbinding and transactivation activities of p53 (Jayaraman et al. 1997) further stresses the potential functional importance of the redox state of p53. It is unknown whether the redox state of p53 influences the post-translational modifications of p53 discussed above. Finally, emphasizing the continuing interaction of p53 and redox status in all aspects of $p 53$ signaling pathways, it has been suggested that p53-mediated induction of genes involved in the generation of reactive oxygen generation contributes to p53-mediated apoptosis (Polyak et al. 1997). Continued characterization of the interpl ay between intracellular redox status and p53 induction and function is likely to be an informative avenue of investigation in the future.

\section{Alterations in p53 intracellular localization}

To bind to DNA and activate transcription, p53 must be located in the nucleus. Cell lines derived from certain tumors, such as germ cells and neuroblastomas, have significant amounts of p53 protein in the cytoplasm and it has been suggested that this a potential mechanism of inactivating p53 function even in the presence of wildtype gene sequences (M oll et al. 1992, 1995). Though the cytoplasmic p53 protein in these cells is al most certainly inactive, DNA damage does appear to induce p53 levels and function in the nucleus (Goldman et al. 1996). N evertheless, intracellular transport of p53 remains a potential important mechanism of functional regulation and it has recently been suggested that part of the influence of $\mathrm{Mdm} 2$ on p53 proteolysis is its ability to enhance transport of p53 protein out of the nucl eus and into the cytoplasm where it is targeted for degradation (Roth et al. 1998).
Figure 2. Schema of post-translational modifications of p53 that have been reported to occur in vivo in response to DNA damage. IR induces phosphorylation of serine 15 and dephosphorylation of serine 376 in an ATM-dependent manner. UV induces serine 15 phosphorylation in an ATM-independent mechanism. Both IR and UV lead to acetylation of lysine 382 and acetylation of Iysine 320 has been demonstrated in vitro. UV, but not IR, induces phosphorylation of serine 392, a modification which has been implicated in the generation of active p53 tetramers.

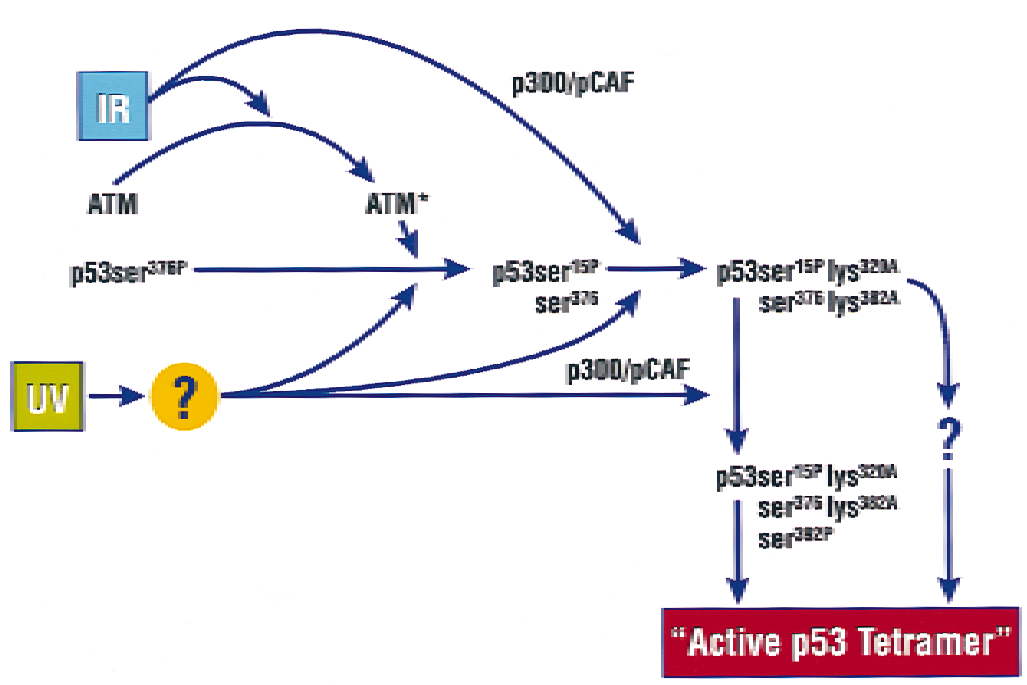


Binding proteins that modulate p53 activity

A final mechanism of modulating p53 activities to consider is via the binding of other intracellular proteins. $\mathrm{N}$ umerous viral and cellular proteins interact with p53 and, as illustrated above, can work by a number of different mechanisms, including altering the rate of p53 degradation, influencing the DNA-binding or transcriptional capabilities of p53, or affecting the intracellular local ization of p53. Some proteins, such as M dm2, which appears to have effects on p53 protein local ization, halflife, and transcriptional activity, may work by multiple mechanisms. Alternatively, a variety of different proteins may affect the same function. For example, similar to the interactions of p53 with histone acetylases, the recent demonstration that $\mathrm{HMG}-1$ binds to and activates p53 (Jayaraman et al. 1998) al so implicates it in the transcriptional activation function of p53. Similarly, the interaction of Ref-1 with p53 (Jayaraman et al. 1997) was initially identified because of its ability to enhance the sequence-specific DNA binding of p53. However, whether Ref- 1 is influencing p53 function by affecting redox status or by some other mechanism remains uncertain. A novel protein that binds to p53, p33 ${ }^{\mathrm{NG} \text {, }}$, was cloned recently using a screen for genetic suppressor elements (Garkavtsev et al. 1998). Preliminary investigations suggest that the growth suppressi ve effects of IN G 1 and p53 are interrel ated and require the activity of both gene products, although the mechanism of this interdependence remains uncertain. p53 has also been reported to bind to replication protein A (Dutta et al. 1993; A bramova et al. 1997); however, the physiologic ramifications of this binding remain unclear. A gain, emphasizing the theme that these different mechanisms of modulating p53 function appear to be interactive with each other, many of these binding proteins will work by altering one or more of the processes discussed above, such as directly or indirectly affecting p53 half-life. Furthermore, phosphorylation events will likely affect some of these interactions (e.g., M dm2 binding) or these interactions could affect a post-translational modification, such as acetylation. A final level of complexity to consider is that post-translational modifications of these binding proteins may affect their ability to interact with p53. Examples of this include the reports that phosphorylation of Mdm2 by DNA-PK will inhibit its ability to bind to p53 (Mayo et al. 1997) and that DN A damage-induced phosphorylation of replication protein A (RPA) inhibits its ability to bind p53 (Abramova et al. 1997).

\section{Specific mechanisms involved in specific signaling pathways}

A wide variety of genotoxic and nongenotoxic stimuli induce $\mathrm{p} 53$ protein and activity in cells as listed above. It appears that there will be some shared mechanisms of p53 induction and activation with these various stimuli and some unique mechanisms (Fig. 3). For example, the ATM kinase appears to be important for p53 induction following IR, but not following UV radiation (Khanna and Lavin 1993; Canman et al. 1994; Siliciano et al. 1997). HIF-1 $\alpha$ may play an important role in p53 induction during hypoxia, but is probably not involved with the other stimuli. Mdm2 interactions with p53 are altered after both DN A damage and oncogene activation, but apparently by different mechanisms (Shieh et al. 1997; de Stanchina et al. 1998; Zindy et al. 1998). In the following sections we discuss what is known about the details of signal ing to p53 from different stimuli. The signaling mechanisms used by activated oncogenes will not be covered because they are discussed in detail in the accompanying review by Sherr (1998). It is worth noting, however, that oncogene signaling via p19Arf depends at least in part on $\mathrm{Mdm} 2$ interactions with p53 but, unlike the p53 induction seen after DNA damage, serine 15 phosphorylation is not altered (de Stanchina et al. 1998).

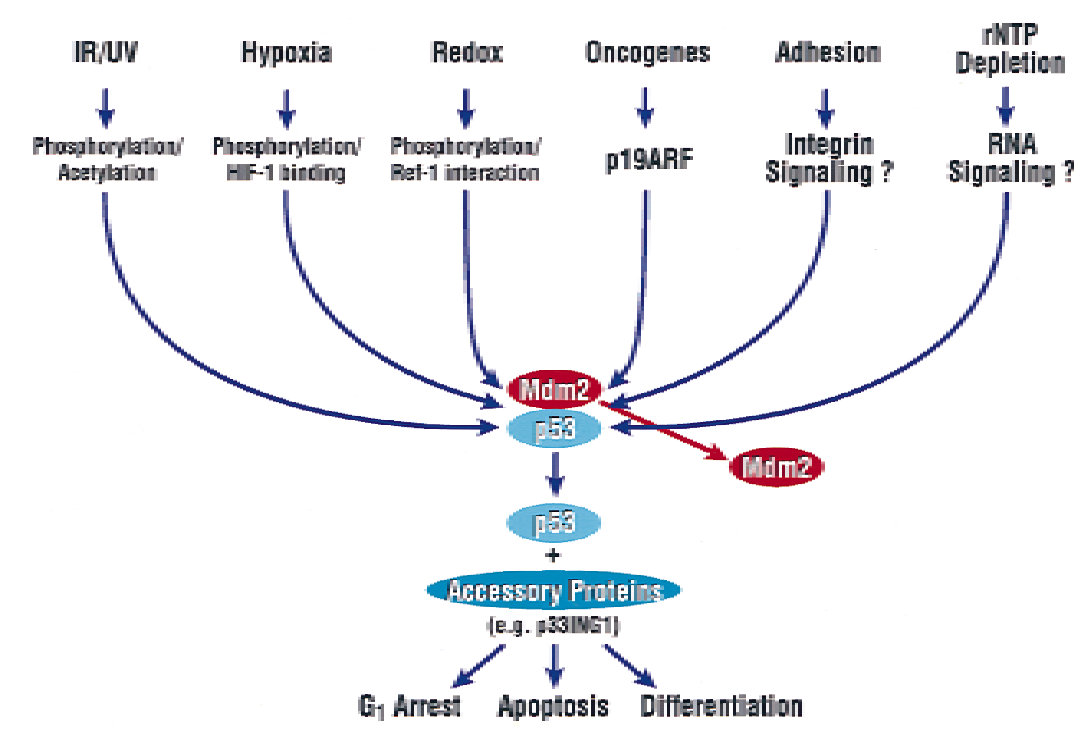

Figure 3. Schema matching stimuli that activate p53 with experimentally demonstrated or hypothetical post-translational modifications and protein-protein interactions (see text for details). 
DN A strand breaks appear to be a signal sufficient for the induction of p53 (Huang et al. 1996; N el son and Kastan 1994), but it remains to be formally demonstrated that IR induces p53 solely by the DN A strand breaks caused by the generation of ROS. Though exact mechanisms remain to be clarified, the increase in p53 protein levels following IR appears to result from a combination of increased protein half-life and increased mRNA translation (see above). It has been known for some time that induction of p53 by IR is suboptimal in cells that lack the expression of the ATM kinase (Kastan et al. 1992; Khanna and Lavin 1993). Recently, this concept was extended by the demonstrations that IR induces phosphorylation of serine 15 (Shieh et al . 1997; Siliciano et al. 1997) and that this post-translational modification is decreased markedly after IR in cells lacking ATM (Siliciano et al. 1997). It should be noted, however, that ATM-null cells exhibit some serine 15 phosphorylation after IR, suggesting the presence of a "back-up" kinase or intermediate kinase (Siliciano et al. 1997; Canman et al. 1998). Prives and colleagues suggested that this phosphorylation event could contribute to both increased p53 half-life and increased p53 transcriptional activity by decreasing the ability of Mdm2 to bind to p53 (Shieh et al. 1997). Consistent with this notion, it was demonstrated that, whereas unphosphoryl ated p53 had a DN A binding capacity similar to the phosphorylated p53 induced by DNA damage, p53 transcriptional activity was correlated with serine 15 phosphorylation by only being evident in the damaged cells (Siliciano et al. 1997).

The importance of the ATM kinase in this IR-induced signaling pathway (Fig. 2) was further established by the recent demonstration that ATM kinase is capable of phosphorylating p53 in vitro on serine 15 and that the ATM kinase activity is enhanced following IR (Canman et al. 1998; Banin et al. 1998). These results suggested that ATM was directly phosphorylating p53 on this site in response to IR. Because ATM is important in a variety of cellular responses to IR that do not involve p53 protein (M organ and Kastan 1997), it is likely that there will be other targets for the ATM kinase as well. Interestingly, ATM was also implicated in a radiation-induced dephosphorylation event (Fig. 2). IR causes a loss of a phosphate group from serine 376 in the carboxyl terminus of p53 in an ATM-dependent manner and this dephosphorylation event results in creation of a binding site for 14-3-3 proteins and enhancement of sequence specific DN A binding (Waterman et al. 1998). Although it is unlikely that the ATM protein has intrinsic phosphatase activity, it is conceivablethat a phosphatase that acts on serine 376 is activated by ATM after IR. Finally, it has been suggested recently that DNA-PK activity is necessary but not sufficient for induction of p53 DNAbinding and transcriptional activity, but does not participate in the damage-induced increase in p53 protein levels (Woo et al. 1998). Although it remains to be determined how DNA-PK influences this activity and whether it is a direct or indirect effect, these observa- tions support the concept that there is more to p53 activation after DNA damage than the simple increase in p53 protein levels.

As discussed above, there are many other potential phosphorylation sites in the 553 protein, but their modulation in response to various stimuli is just beginning to be elucidated. Topoi somerase inhibitors that al so create strand breaks in DNA, such as etoposide or camptothecin, have been shown to activate a kinase which phosphorylates a site in the amino terminus of p53 and casein kinase I has been implicated as the likely kinase (Knippschild et al. 1997). Whether this is the same site previously identified as the second IR-induced phosphorylation site in the amino-terminal region of p53 (Siliciano et al. 1997) and whether CKI is the actual in vivo kinase remains to be clarified. IR-induced phosphorylation of serine 33 has al so recently been reported, al though the in vivo kinase has not been clarified (Sakaguchi et al. 1998). Interestingly, CAK has been shown to phosphorylate serine 33 in vitro (Ko et al. 1997) and would be an attractive candidate for such an IR-induced event; however, CAK has also been reported to phosphorylate carboxy-terminal serines in p53 and stimulate its sequence-specific DN A binding (Lu et al. 1997). The role of CAK in phosphorylating one or more of these sites in response to IR or other stimuli in vivo remains to be clarified.

In addition to the induction of serine 15 phosphorylation and serine 376 dephosphorylation, the other posttranslational modification shown to occur in vivo in response to the exposure of cells to IR is the acetylation of lysine 382 (Sakaguchi et al. 1998) (Fig. 2). Because this acetylation event appears to be influenced by the phosphorylation status of certain serines, the concept that such post-translational modifications are working in a coordinate manner is supported.

\section{$\mathrm{U} \mathrm{V}$ radiation}

UV-C irradiation is also a potent inducer of p53 protein and the signaling mechanisms used by UV radiation appear to have some steps in common and some steps that are distinct from those involved in signaling to p53 after IR. It has been suggested that, similar to IR, the initial signal leading to p53 induction after UV treatment is dependent on the generation of DNA strand breaks. In the case of UV, these strand breaks appear to be caused either by excision repair or replication past thymine dimers and the signal does not appear to be the damaged DN A bases themsel ves (N elson and Kastan 1994). However, it has al so been suggested that UV si gnals to $\mathrm{p53}$ via the generation of thymine dimer-induced stalled transcription complexes (Ljungman and Zhang 1996; Dumaz et al. 1997). The induction of acetylation of Iysines 320 and 382 appears to also be shared by IR and UV radiation (Sakaguchi et al. 1998).

However, clear differences exist in p53 induction following UV radiation versus IR. For example, UV signaling to p53 does not depend on the ATM kinase. Both induction of p53 (Khanna and Lavin 1993; Canman et al. 1994) and phosphorylation of serine 15 (Siliciano et al. 
1997) occur in ataxia-telangiectasia (AT) cells after UV irradiation. Interestingly, this latter observati on suggests that a different kinase is induced by UV than IR, but that this UV-induced kinase is capable of phosphorylating the same site (Fig. 2). Additionally, in contrast to IR, UV irradiation does not increase ATM kinase activity in the cell (Canman et al. 1998). A second distinction between UV and IR appears to be the induction of serine 392 (human) phosphorylation, which is observed following UV, but not IR (Kapoor and Lozano 1998; Lu et al. 1998). Interestingly, this phosphorylation event is associated with increased sequence-specific DN A binding (Kapoor and Lozano 1998; Lu et al. 1998) and has been suggested to stabilize tetramer formation of p53 (Sakaguchi et al. 1997). As this phosphorylation event does not appear to be occurring following IR, some other events after IR must compensate for the lack of this particular modification such that IR can al so lead to enhanced tetramer formation, DN A binding, and transcriptional activation. Differences in some of the p53-induced downstream events, such as cell cycle arrest and apoptosis, al so exist between IR and UV, but the dependence of these differences on distinct post-translational modifications or binding proteins remain to be clarified.

\section{Hypoxia}

Similar to IR, low oxygen conditions cause the nuclear accumulation of p53 and increase the DN A-binding and transactivation activity of wild-type p53 in cells (Graeber et al. 1994; Kim et al . 1997). However, unlike IR, the accumulation of cells in $G_{1}$ phase by hypoxia is not dependent solely on wild-type p53 function at low oxygen conditions (0.02\% oxygen) (Graeber et al. 1994; Green and Giaccia 1998). These results suggest that there are multiple pathways leading to cell cycle growth arrest, and that the signal transduction pathway for growth arrest induced by hypoxia is at least partially distinct from the signal transduction pathway for growth arrest induced by IR (Fig. 3).

What is the trigger for p53 induction under low oxygen conditions? Hypoxia is unlikely to cause DN A damage di rectly, and little to no evidence exists for indirect damage to DNA. One group has reported increased endonuclease activity in lysates isol ated from chronically anoxic fibroblasts (cells that were cultured in the compl ete absence of oxygen for $16 \mathrm{hr}$ or more) (Stoler et al. 1992). However, they were unable to measure any increase in cellular DNA strand breaks generated in anoxia-treated cells as compared to untreated cells, and suggested that the endonuclease(s) induced by anoxia may be secreted by anoxic fibroblasts during wound debridement and healing. The possibility that some DNA damage, undetectable by present biochemical assays, is caused by hypoxia cannot be ruled out. However, DNA damage is not the primary insult of hypoxia and yet hypoxia causes p53 accumulation of the same magnitude as that caused by ionizing radiation for treatments with similar or lower cytotoxi cities (Graeber et al. 1994), again arguing against DNA damage being the trigger for p53 accumulation by hypoxia. The increase of p53 in response to hypoxia is also not a result of a general stress-induced increase in protein synthesis as hypoxia causes a reduction in overall cellular protein synthesis (McCormick and Penman 1969; Heacock and Sutherland 1986; Pettersen et al. 1986). Thus the mechanism for the induction of p53 under low oxygen conditions is different than that for DNA damage.

Although DN A damage does not seem to be the signal for p53 induction under hypoxia, preliminary studies suggest that p53 is phosphorylated at serine 15 under hypoxic conditions (C. Koumenis, J. Siliciano, R. Alarcon, Y. Taya, M. Kastan, and A. Giaccia, unpubl.). Whether other sites are phosphorylated is still unknown, but this result further supports the significance of serine 15 phosphorylation in p53 stabilization. In addition, studies from several groups have al so suggested that re dox-sensitive proteins such as HIF- $1 \alpha$ (An et al. 1998) and Ref-1 (Jayaraman et al. 1997) can interact with p53 and alter its activity or levels. As both of these proteins are redox sensitive, the implication of these observations is that redox stress, whether it be oxidative or reductive in nature, will activate redox-sensitive proteins that will stabilize p53 protein levels. Future studies will be required to understand the role of protein phosphorylation and protein-protein interaction in p53 stabilization under hypoxic conditions, and how these interactions affect p53's biological activity in promoting apoptosis (Graeber et al. 1996; Kim et al. 1997).

\section{Cell adhesion}

The paradigm for p53 regulati on by stress emanates from the analysis of tumor cells, and transformed and untransformed fibroblasts and lymphocytes. In these cell types, the level of p53 protein in unstressed cells is low but, upon exposure to stress, becomes elevated. Several reports suggest that p53 regulation in epithelial cells and kerati nocytes deviates from this paradigm (Delmol ino et al. 1993; Girinsky et al. 1995; Weinberg et al. 1995; N igro et al. 1997) and are highly susceptible to changes in cell attachment ( $\mathrm{N}$ igro et al . 1997). Thus, cell adhesion pathways play an important role in modulating p53 expression through an as yet undefined signal transduction pathway, most probably originating from cell surface changes in adhesion molecule expression. Further studies will be required to understand the interpl ay between cell adhesion signaling to p53 and how it affects signaling to p53 by other forms of stress.

\section{Decreased rNTP}

Depletion of ribonucleotide (rNTP) pools activates p53 through a DNA damage-independent signaling pathway (Linke et al. 1996). Although this supposition is supported by experimental evidence, it is now possible to investigate this question more biochemically with regard to p53 modifications that are induced by this metabolic stress. The signaling mechanism and the actual metabolic signal for induction of p53 by rNTP is un- 
known, but it may lead to a novel pathway for p53 activation that could be used to pharmacologi cally modulate p53 independent of traditionally empl oyed chemotherapeutic agents.

\section{Conclusion}

The wide range of genetic, environmental, and metabolic stimuli that activate p53 clearly distinguishes it from other known tumor suppressor genes. p53 both senses stress-promoting conditions, be they internal or external, and signals the appropriate response in a stress- and cell type-specific manner. Increasing our knowledge of the different signal transduction pathways and mechanisms of p53 activation used by different stresses will allow the future design of critical and specific modulators of p53 activity. The next challenge will be to selectively modulate p53 activity under pathophysiological conditions that generate redox stress to prevent tissue damage, or in tumors to restore sensitivity to anti-cancer therapeutics.

\section{Acknowledgments}

We thank Christine Canman and Costas Koumenis for hel pful discussions. This work is supported by $\mathrm{N}$ ational Institutes of Health (NIH) grants (PO1-CA67166, RO1-CA64489, RO1CA 73832) and by the American Cancer Society to A.J.G. M.B.K. is The Steven Birnbaum Scholar of the Leukemia Society of America and is supported by NIH grants (CA 71387, ES05777, and CA 77715) and the American Lebanese Syrian Associated Charities (ALSAC) of St. Jude Children's Research Hospital.

\section{References}

Abramova, N.A., J. Russell, M. Botchan, and R. Li. 1997. Interaction between replication protein $A$ and p53 is disrupted after UV damage in a DN A repair-dependent manner. Proc. Natl. Acad. Sci. 94: 7186-7191.

An, W.G., M. Kanekal, M.C. Simon, E. Maltepe, M.V. BlagoskIonny, and L.M. Neckers. 1998. Stabilization of wild-type p53 by hypoxia-inducible factor 1a. Nature 392: 405-408.

Antoniades, H.N., T. Galanopoulos, J. Neville-Golden, C.P. Kirtsy, and S.E. Lynch. 1994. p53 expression during normal tissue regeneration in reponse to acute cutaneous injury in swine. J. Clin. Invest. 93: 2206-2214.

Avantaggiati, M.L., V. Ogryzko, K. Gardner, A. Giordano, A.S. Levine, and K. Kelly. 1997. Recruitment of p300/CBP in p53dependent signal pathways. Cell 89: 1175-1184.

Banasiak, K.J. and G.G. Haddad. 1998. Hypoxia-induced apoptosis:effect of hypoxia severity and role of p53 in neuronal cell death. Brain Res. 797: 295-304.

Banin, S., L. Moyal, R. Khostravi, S.-Y. Shieh, Y. Taya, C.W. Anderson, L. Chessa, N .I. Smorodinsky, C. Prives, Y. Shiloh, and Y. Ziv. 1998. Enhanced phosphorylation of p53 by ATM in response to DNA damage. Science (in press).

Baudier, J., C. Delphin, D. Grunwald, S. Khochbin, and J.J. Lawrence. 1992. Characterization of the tumor suppressor protein p53 as a protein kinase C substrate and a S100bbinding protein. Proc. Natl. Acad. Sci. 89: 11627-11631.

Bischoff, J.R., P.N. Friedman, D.R. M arshak, C. Prives, and D. Beach. 1990. Human p53 is phosphorylated by p60-cdc2 and cyclin B-cdc2. Proc. Natl. Acad. Sci. 87: 4766-4770.

Calmels, S., P. Hainaut, and H. Ohshima. 1997. Nitric oxide induces conformational and functional modifications of wild-type p53 tumor suppressor protein. Cancer Res. 57: 3365-3369.

Canman, C.E., A.C. Wolff, C.Y. Chen, A.J.J. Fornace, and M.B. Kastan. 1994. The p53-dependent G1 cell cycle checkpoint pathway and ataxia-telangiectasia. Cancer Res. 54: 5054-5058.

Canman, C.E., D.S. Lim, K.A. Cimprich, Y. Taya, K. Tamai, K. Sakaguchi, E. Appella, M.B. Kastan, and D.D. Siliciano. 1998. Activation of the ATM kinase by ionizing radiation and phosphorylation of $\mathrm{p53}$. Science (in press).

Chernov, M.V., C.V. Ramana, V.V. Adler, and G.R. Stark. 1998. Stabilization and activation of p53 are regulated independently by different phosphorylation events. Proc. Natl. Acad. Sci. 95: 2284-2289.

Cho, Y., S. Gorina, P.D. Jeffrey, and N .P. Pavletich. 1994. Crystal structure of a p53 tumor suppressor-DN A complex: understanding tumorigenic mutations. Science 265: 346-355.

Debbas, M. and E. White. 1993. Wild-type p53 mediates apoptosis by E1A, which is inhibited by E1B. Genes \& Dev. 7: 546-554.

Delmolino, L., H. Band, and V. Band. 1993. Expression and stability of p53 protein in human mammary epithelial cells. Carcinogenesis 14: 827-832.

Del phin, C., P. Cahen, J.J. Lawrence, and J. Baudier. 1994. Characterization of baculovirus recombinant wild-type p53. Dimerization of p53 is required for high-affinity DNA binding and cysteine oxidation inhibits p53 DNA binding. Eur. J. Biochem. 223: 683-692.

de Stanchina, E., M.E. McCurrach, F. Zindy, S.-Y. Shieh, G. Ferbeyte, A.V. Samulsen, C. Prives, M.F. Roussel, C.J. Sherr, and S.W. Lowe. 1998. E1A signaling to p53 involves the p19ARF tumor suppressor. Genes \& Dev. 12: 2434-2442.

Dumaz, N., A. Duthu, J.C. Ehrhart, C. Drougard, E. Appella, C.W. Anderson, P. May, A. Sarasin, and L. Daya-Grosjean. 1997. Prolonged p53 protein accumulation in trichothiodystrophy fibroblasts dependent on unrepaired pyrimidine domers on the transcribed strands of cellular genes. Mol. Carcinog. 20: 340-347.

Dutta, A., J.M. Ruppert, J.C. Aster, and E. Winchester. 1993. Inhibition of DNA replication factor RPA by p53. Nature 365: 79-82.

Eckner, R., M .E. Ewen, D. N ewsome, M. Gerdes, J.A. DeCaprio, J.B. Lawrence, and D.M. Livingston. 1994. M olecular cloning and functional analysis of the adenovirus E1A-associated $300-k D$ protein (p300) reveals a protein with properties of a transcriptional adaptor. Genes \& Dev. 8: 869-884.

Eckner, R., J.W. Ludlow, N.L. Lill, E. Oldread, Z. Arany, N. Modjtahedi, J.A. DeCaprio, D.M. Livingston, and J.A. Morgan. 1996. Association of p300 and CBP with simian virus 40 large $T$ antigen. Mol. Cell. Biol. 16: 3454-3464.

Fu, L. and S. Benchimol. 1997. Participation of the human p53 3' UTR translational repression and activation following gamma-irradiation. EMBO J. 16: 4117-4125.

Garkavtsev, I., I.A. Grigorian, V.S. Ossovskaya, M.V. Chernov, and A.V. Gudkov. 1998. The candidate tumor suppressor p33IN G 1 cooperates with p53 in cell growth control. Nature 391: 295-298.

Girinsky, T., C. Koumenis, T.G. Graeber, D.M. Peehl, and A.J. Giaccia. 1995. Attenuated response of p53 and p21 in primary cultures of human prostatic epithelial cells exposed to DN A-damaging agents. Cancer Res. 55: 3726-3731.

Goldman, S.C., C.Y. Chen, T.J. Lansing, T.M. Gilmer, and M.B. Kastan. 1996. The p53 signal transduction pathway is intact 
in human neuroblastoma despite cytoplasmic localization. Am. J. Pathol. 148: 1381-1385.

Gottleib, T.M. and M. Oren. 1995. p53 in growth control and neoplasia. Biochim. Biophys. Acta 1287: 77-102.

Graeber, T.G., J.F. Peterson, M. Tsai, A.J. Fornace, Jr., and A.J. Giaccia. 1994. Hypoxia induces the accumulation of p53 protein, but the activation of a G1-phase checkpoint by low oxygen conditions is independent of p53 status. Mol. Cell Biol. 14: 6264-6277.

Graeber, T.G., C. Osmanian, T. Jacks, D.E. Housman, C.J. Koch, S.W. Lowe, and A.J. Giaccia. 1996. Hypoxia mediated selection of cells with diminished apoptotic potential in solid tumors. Nature 379: 88-91.

Green, S.L. and A.J. Giaccia. 1998. Tumor hypoxia and the cell cycle: Implications for malignant progression and response to therapy. Cancer J. Sci. Am. 4: 218-223.

$\mathrm{Gu}$, W. and R.G. Roeder. 1997. Activation of p53 sequencespecific DNA binding by acetylation of the p53 C-terminal domain. Cell 90: 595-606.

Gu, W., X.-L. Shi, and R.G. Roeder. 1997. Synergistic activation of transcription by CBP and p53. Nature 387: 819-822.

Hainaut, P. and J. Milner. 1993a. A structural rolefor metal ions in the "wild-type" conformation of the tumor suppresor protein p53. Cancer Res. 53: 1739-1742.

- - - 1993b. Redox modulation of p53 conformation and sequence-specific DNA binding in vitro. Cancer Res. 53: 4469-4473.

Hall, S.R., L.E. Campbell, and D.W. Meek. 1996. Phosphorylation of p53 at the casein kinase II site selectively regulates p53-dependent transcriptional represssion but not transactivation. Nucleic Acids Res. 24: 1119-1126.

Haupt, Y., R. Maya, A. Kazaz, and M. Oren. 1997. Mdm2 promotes the rapid degradation of p53. Nature 387: 296-299.

Heacock, C.S. and R.M. Sutherland. 1986. Induction characteristics of oxygen regulated proteins. Int. J. Radiat. Oncol. Biol. Phys. 12: 1287-1290.

Hermeking, H. and D. Eick. 1994. Mediation of c-myc induced apoptosis by p53. Science 265: 2091-2093.

Honda, R., H. Tanaka, and H. Yasuda. 1997. Oncoprotein MDM 2 is a ubiquitin ligase E3 for tumor suppressor p53. FEBS Lett. 420: 25-27.

Huang, L.C., K.C. Clarkin, and G.M. Wahl. 1996. Sensitivity and selectivity of the DNA damage sensor responsible for activating p53-dependent G1-arrest. Proc. Natl. Acad. Sci. 93: 4827-4832.

Hupp, T.R. and D.P. Lane. 1994. Regulation of the crytic sequence-specific DNA binding function of p53 by protein kinases. Cold Spring Harb. Symp. Q uant. Biol. 59: 195-206.

Hupp, T.R., D.W. Meek, C.A. Midgley, and D.P. Lane. 1993. Activation of the cryptic DNA binding function of mutant forms of p53. Nucleic Acids Res. 21: 3167-3174.

Hupp, T.R., A. Sparks, and D.P. Lane. 1995. Small peptides activate the latent sequence-specific DN A binding function of p53. Cell 83: 237-245.

Jayaraman, L. and C. Prives. 1995. Activation of p53 sequencespecific DNA binding by short single strands of DNA requires the C-terminus. Cell 81: 1021-1029.

Jayaraman, L., K.G. Murthy, C. Zhu, T. Curran, S. Xanthoudakis, and C. Prives. 1997. Identification of redox/repair protein Ref-1 as a potent activator of p53. Genes \& Dev. 11: $558-570$.

Jayaraman, L., N.C. Moorthy, K.G. Murthy, J.L. Manley, M. Bustin, and C. Prives. 1998. High mobility group protein-1 (HM G-1) is a unique activator of p53. Genes \& Dev. 12: 462472.

Kamijo, T., J.D. Weber, G. Zambetti, F. Zindy, M.F. Roussel, and C.J. Sherr. 1998. Functional and physical interactions of the ARF tumor suppressor with p53 and M dm2. Proc. Natl. Acad. Sci. 95: 8292-8297.

Kapoor, M. and G. Lozano. 1998. Functional activation of p53 via phosphorylation following DNA damage by UV but not gamma radiation. Proc. Natl. Acad. Sci. 95: 2834-2837.

Kastan, M.B., O. Onyekwere, D. Sidransky, B. Vogelstein, and R.W. Craig. 1991. Participation of p53 in the cellular re sponse to DNA damage. Cancer Res. 51: 6304-6311.

Kastan, M.B., Q. Zhan, W. El-Diery, F. Carrier, T. Jacks, W.V. Walsh, B.S. Plunkett, B. Vogelstein, and A.J. Fornace. 1992. A mammalian cell-cycle checkpoint pathway utilizing p53 and gadd45 is defective in Ataxia-Telangiectasia. Cell 71: 587597.

Khanna, K.K. and M.F. Lavin. 1993. Ionizing radiation and UV induction of $\mathrm{p} 53$ protein by different pathways in ataxia telangiectasia cells. Oncogene 8: 3307-3312.

Kim, C.Y., M.H. Tsai, C. Osmanian, T.G. Graeber, J.E. Lee, R.G. Giffard, J.A. DiPaolo, D.M. Peehl, and A.J. Giaccia. 1997. Selection of human cervical epithelial cells that possess reduced apoptotic potential to low-oxygen conditions. Cancer Res. 57: 4200-4204.

Knippschild, U., D.M. Milne, L.E. Campbell, A.J. DeM aggio, E. Christenson, M.F. Hoekstra, and D.W. Meek. 1997. p53 is phosphorylated in vitro and in vivo by the delta and epsilon isoforms of casein kinase I and enhances the level of casein kinase I delta in response to topoisomerase-directed drugs. Oncogene 15: 1727-1736.

Ko, L.J. and C. Prives. 1996. p53: Puzzle and paradigm. Genes \& Dev. 10: 1054-1072.

Ko, L.J., S.Y. Shieh, X. Chen, L. Jayaraman, K. Tamai, Y. Taya, C. Prives, and Z.Q. Pan. 1997. p53 is phosphorylated by CDK7-cyclin $\mathrm{H}$ in a p36MAT1-dependent manner. Mol. Cell. Biol. 17: 7220-7229.

Kubbutat, M.H., S.N. Jones, and K.H. Vousden. 1997. Regulation of p53 stability by Mdm2. Nature 387: 299-303.

Lee, S., B. Elenbass, A. Levine, and J. Griffith. 1995. p53 and its $14 \mathrm{kDa}$ C-terminal domain recognize primary DNA damage in the form of insertion/deletion mismatches. Cell 81: 1013-1020.

Lees-Miller, S.P., Y.-R. Chen, and C.W. Anderson. 1990. Human cells contain a DNA-activated protein kinase that phosphorylates simian virus $40 \mathrm{~T}$ antigen, mouse p53, and the human Ku autoantigen. Mol. Cell. Biol.10: 6472-6481.

Levine, A.J. 1997. p53, the cellular gatekeper for growth and division. Cell 88: 323-331.

Lill, N.L., S.R. Grossman, D. Ginsberg, J. DeCaprio, and D.M. Livingston. 1997a. Binding and modulation of p53 by p300/ CBP coactivators. Nature 387: 823-827.

Lill, N.L., M.J. Tevethia, R. Eckner, D.M. Livingston, and N. M odjtahedi. 1997b. p300 family members associate with the carboxyl terminus of sivian virus 40 large tumor antigen. J. Virol. 71: 129-137.

Linke, S.P., K.C. Clarkin, A. DiLeonardo, A. Tsou, and G.M. Wahl. 1996. A reversible, p53 dependent G0/G1 cell cycle arrest induced by ribonucleotide depletion in the absence of detectable DNA damage. Genes \& Dev. 10: 934-947.

Ljungman, M. and F. Zhang. 1996. Blockage of RN A polymerase as a possible trigger for UV light-induced apoptosis. Oncogene 13: 823-831.

Lowe, S.W. and H.E. Ruley. 1993. Stabilization of the p53 tumor suppressor is induced by adenovirus $5 \mathrm{E} 1 \mathrm{~A}$ and accompanies apoptosis. Genes \& Dev. 7: 535-545.

Lu, H. and A.J. Levine. 1995. Human TAFII31 protein is a transcriptional coactivator of the p53 protein. Proc. Natl. Acad. Sci. 92: 5154-5158. 
Lu, H., R.P. Fisher, P. Bailey, and A.J. Levine. 1997. The CDKcycH-p36 complex of transcription factor IIH phosphorylates p53, enhances its sequence-specific DN A binding activity in vitro. Mol. Cell. Biol. 17: 5923-5934.

Lu, H., Y. Taya, M. Ikeda, and A.J. Levine. 1998. Ultraviolet radiation, but not gamma radiation or etoposide-induced DNA damage, results in the phosphorylation of the murine p53 at serine-389. Proc. Natl. Acad. Sci. 95: 6399-6402.

Maki, C.G. and P.M. Howley. 1997. Ubiquitination of p53 and p21 is differentially affected by ionizing radiation and UV radiation. Mol. Cell. Biol. 17: 355-363.

Maki, C.G., J.M. Huibregtse, and P.M. Howley. 1996. In vivo ubiquitination and proteasome-mediated degradation of p53(1). Cancer Res. 56: 2649-2654.

Maltzman, W. and L. Czyzyk. 1984. UV irradiation stimulates levels of p53 cellular tumor antigen in nontransformed mouse cells. Mol. Cell. Biol. 4: 1689-1694.

Mayo, L.D., J.J. Turchi, and S.J. Berberich. 1997. M dm-2 phosphorylation by DNA-dependent protein kinase prevents interaction wih p53. Cancer Res. 57: 5013-5016.

McCormick, W. and S. Penman. 1969. Regulation of protein synthesis in HeLa cells: Translation at elevated temperatures. J. Mol. Biol. 39: 315-333.

Midgley, C.A. and D.P. Lane. 1997. p53 protein stability in tumor cells is not determined by mutation but is dependent on Mdm2 binding. Oncogene 15: 1179-1189.

Milne, D.M., R.H. Palmer, D.G. Campbell, and D.W. Meek. 1992. Phosphorylation of the p53 tumor-suppressor protein at three $\mathrm{N}$-terminal sites by a novel casein kinase I-like enzyme. Oncogene 7: 1361-1369.

Moll, U.M., G. Riou, and A.J. Levine. 1992. Two distinct mechanisms alter p53 in breast cancer: Mutation and nuclear exclusion. Proc. Natl. Acad. Sci. 89: 7262-7266.

Moll, U.M., M. LaQuaglia, J. Benard, and G. Riou. 1995. Wildtype p53 protein undergoes cytoplasmic sequestration in undifferentiated neuroblastomas but not in differentiated tumors. Proc. Natl. Acad. Sci. 92: 4407-4411.

Momand, J., G.P. Zambetti, D.C. Olson, D.L. Geoge, and A.J. Levine. 1992. The mdm-2 oncogene product forms a complex with the p53 protein and inhibits p53-mediated transactivaton. Cell 69: 1237-1245.

M organ, S.E. and M.B. Kastan. 1997. p53 and ATM : Cell cycle, cell death and cancer. Adv. Cancer Res. 71: 1-25.

M osner, J., T. M ummenbrauer, C. Bauer, G. Sczakiel, F. Grosse, and W. Deppert. 1995. N egative feedback regulation of wildtype p53 biosynthesis. EMBO J. 14: 4442-4449.

Muller-Tiemann, B.F., T.D. Halazonetis, and J.J. Elting. 1998. Identification of an additional negative regulatory region for p53 sequence-specific DNA binding. Proc. Natl. Acad. Sci. 95: 6079-6084.

Nelson, W.G. and M. Kastan. 1994. DNA strand breaks: the DN A template alterations that trigger p53-dependent DNA damage response pathways. Mol. Cell. Biol. 14: 1815-1823.

Nigro, J.M ., K.D. Aldape, S.M. Hess, and T.D. TIsty. 1997. Cellular adhesion regulates p53 protein levels in primary human keatinocytes. Cancer Res. 57: 3635-3639.

Oliner, J.D., J.A. Pietenpol, S. Thiagalingam, J. Gyuris, K.W. Kinzler, and B. Vogelstein. 1993. Oncoprotein MDM 2 conceals the activation domain of tumor suppressor p53. Nature 362: 857-860.

Pearson, G.D. and G.F. Merrill. 1998. Deletion of the Saccharomyces cerevisiae TRR1 gene encoding thioredoxin reductase inhibits p53-dependent reporter gene expression. J. Biol. Chem. 273: 5431-5434.

Pettersen, E.O., N.O. Juul, and O.W. Ronning. 1986. Regulation of protein metabolism of human cells during and after acute hypoxia. Cancer Res. 46: 4346-4351.

Polyak, K., Y. Xia, J.L. Zweier, K.W. Kinzler, and B. Vogelstein. 1997. A model for p53-induced apoptosis. Nature 389: 300305.

Pomerantz, J., N . Schrei ber-Agus, N .J. Li iegeois, A. Silverman, L. Alland, L. Chin, J. Potes, K. Chen, I. Orlow, H.W. Lee, C. Cordon-Cardo, and R.A. DePinho. 1998. The Ink4a tumor suppressor gene product, p19Arf, interacts with MDM 2 and neutralizes MDM2's inhibition of p53. Cell 92: 713-723.

Price, B.D. and S.K. Calderwood. 1993. Increased sequence-specific p53-DN A binding activity after DN A damage is attenuated by phorbol esters. Oncogene 8: 3055-3062.

Price, B.D., L. Hughes-Davies, and S.J. Park. 1995. Cdk2 kinase phosphorylates serine 315 of human p53 in vitro. Oncogene 11: $73-80$.

Roth, J., M. Dobbelstein, D.A. Freedman, T. Shenk, and A.J. Levine. 1998. N ucleo-cytoplasmic shutling of the mdm2 oncoprotein regulates the levels of the $\mathrm{p} 53$ protein via a pathway used by the human immunodeficiency virus rev protein. EMBO J. 17: 554-564.

Sakaguchi, K., H. Sakamoto, M.S. Lewis, C.W. Anderson, J.W. Erickson, E. Apella, and D. Xie. 1997. Phosphorylation of serine 392 stabilizes the tetramer formation of tumor suppressor protein p53. Biochemistry 36: 10117-10124.

Sakaguchi, K., J.E. Herrera, S. Saito, T. Miki, M. Bustin, A. Vassilev, C.W. Anderson, and E. Appella. 1998. DNA damage activates p53 through a phosphorylation-acetylation cascade. Genes \& Dev. 12: 2831-2841.

Scheffner, M., B.A. Werness, J.M. Huibregtse, A.J. Levine, and P.M. Howley. 1990. The E6 oncoprotein encoded by human papillomavirus types 16 and 18 promotes the degradation of p53. Cell 63: 1129-1136.

Schwartz, D., N. Goldfinger, and V. Rotter. 1993. Expression of p53 protein in spermatogenesis is confined to the tetraploid pachytene primary spermatocytes. Oncogene 8: 1487-1494.

Scolnick, D.M., N.H. Chehab, E.S. Stavridi, M.C. Lien, L. Caruso, E. Moran, S.L. Berger, and T.D. Halazonetis. 1997. CREB-binding protein and p300/CBP-assocaited factor are transciptional coactivators of the p53 tumor suppressor protein. Cancer Res. 57: 3693-3696.

Selivanova, G., V. Iotsova, I. Okan, M. Fritsche, M. Storm, B. Groner, R.C. Crafstorm, and K.G. Wilman. 1997. Restoration of the growth suppression function of mutant $\mathrm{p} 53$ by a synthetic peptide derived from p53 C-terminal domain. Nat. Med. 3: 632-638.

Serrano, M., A.W. Lin, M.E. McCurrach, D. Beach, and S.W. Lowe. 1997. Oncogenic ras provokes premature cell senescence associated with accumulation of p53 and p16IN K4a. Cell 88: 593-602.

Sherr, C.J. 1998. Tumor surveillance via the ARF-p53 pathway. Genes \& Dev. (this issue).

Shieh, S.-Y., M. Ikeda, Y. Taya, and C. Prives. 1997. DN A damage-induced phosphorylation of p53 alleviates inhibition by MDM2. Cell 91: 325-334.

Siliciano, J.D., C.E. Canman, Y. Taya, K. Sakaguchi, E. A ppella, and M.B. Kastan. 1997. DNA damage induces phosphorylation of the amino terminus of p53. Genes \& Dev. 11: 34713481.

Steegenga, W.T., T. van Laar, N. Riteco, A. Manarino, A. Shvarts, A.J. van der Eb, and A.G. Jochemsem. 1996. Adenovirus E1A proteins inhibit activation of transcription by $\mathrm{p} 53$. Mol. Cell. Biol. 16: 2101-2109.

Stoler, D.L., G.R. Anderson, C.A. Russo, A.M. Spina, and T.A. Beerman. 1992. A noxia-inducible endonucl ease activity as a potential basis of the genomic instability of cancer cells. Cancer Res. 52: 4372-4378. 
Takenaka, I., F. M orin, B.R. Seizinger, and N. Kley. 1995. Regulation of the sequence-specific DN A binding function of p53 by potein kinase $C$ and protein phosphatases. J. Biol. Chem. 270: 5405-5411.

Thut, C. J., J.-L. Chen, R. Klemm, and R. Tjian. 1995. p53 transcriptional activation mediated by coactivators TAFII40 and TAFII60. Science 267: 100-104.

Thut, C.J., J.A. Goodrich, and R. Tjian. 1997. Repression of p53mediated transription by MDM 2: A dual mechanism. Genes \& Dev. 11: 1974-1986.

Venot, C., M. M aratrat, C. Dureuil, E. Conseiller, L. Bracco, and L. Debussche. 1998. The requirement for the p53 prolinerich functional domain for mediation of apoptosis is correlated with specific PIG3 gene transactivation and with transcriptional repression. EMBO J. 17: 4668-4679.

Verhaegh, G.W., M.J. Richard, and P. Hainaut. 1997. Regulation of p53 by metal ions and by antioxidants: dithiocarbamate down-regulates p53 DN A-binding activity by increasing the intracellular level of copper. Mol. Cell. Biol. 17: 5699-5706.

Wagner, A.J., J.M. Kokontis, and N. Hay. 1994. Myc-mediated apoptosis requires wild-type p53 in a manner independent of cell-cycle arrest and the ability of p53 to induce p21 $1^{\text {waf-1/cip1 }}$. Genes \& Dev. 8: 2817-2830.

Walker, K.K. and A.J. Levine. 1996. Identification of a novel p53 functional domain that is necessary for efficient growth suppression. Proc. Natl. Acad. Sci. 93: 15335-15340.

Waterman, M.J.F., E.S. Stavridi, J.L.F. Waterman, and T.D. Halazonetis. 1998. ATM-dependent activation of p53 involves dephosphorylation and association with 14-3-3 proteins. Nature Genet. 19: 175-178.

Weinberg, W.C., C.G. Azzoli, K. Chapman, A.J. Levine, and S.H. Yuspa. 1995. p53-mediated transcriptional activity increases in differentiating epidermal kearatinocytes in association with decreased p53 protein. Oncogene 10: 2271-2279.

Werness, B.A., A.J. Levine, and P.M. Howley. 1990. Association of human papillomavirus types 16 and 18 proteins with p53. Science 248: 76-79.

Woo, R.A., K.G. McLure, S.P. Lees-Miller, D.E. Rancourt, and P.W.K. Lee. 1998. DNA-dependent protein kinase acts upstream of p53 in response to DN A damage. Nature 394: 700704.

Zhang, Y., Y. Xiong, and W.G. Yarbrough. 1998. ARF promotes MDM 2 degradation and stabilizes p53: ARF-INK4a locus deletion impairs both the $\mathrm{Rb}$ and p53 tumor suppression pathways. Cell 92: 725-734.

Zindy, F., C.M. Eischen, d. Randle, T. Kamijo, J.L. Cleveland, C.J. Sherr, and M.F. Roussel. 1998. Myc signaling via the ARF tumor suppressor regulates p53-dependent apoptosis and immortalization. Genes \& Dev. 12: 2424-2433. 


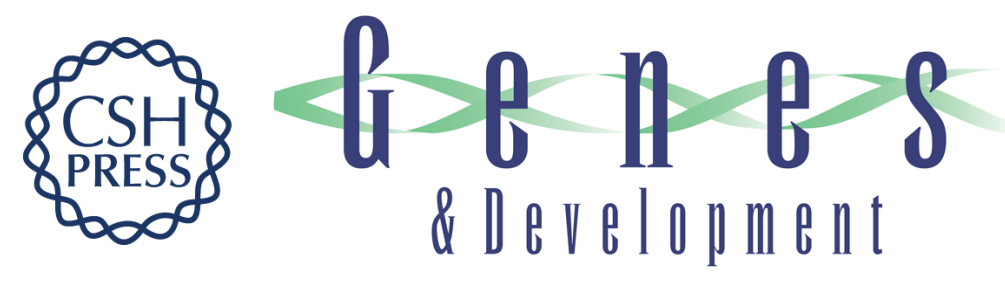

\section{The complexity of p53 modulation: emerging patterns from divergent signals}

Amato J. Giaccia and Michael B. Kastan

Genes Dev. 1998, 12:

Access the most recent version at doi:10.1101/gad.12.19.2973

References This article cites 110 articles, 60 of which can be accessed free at: http://genesdev.cshlp.org/content/12/19/2973.full.html\#ref-list-1

License

Email Alerting

Service

Receive free email alerts when new articles cite this article - sign up in the box at the top right corner of the article or click here.

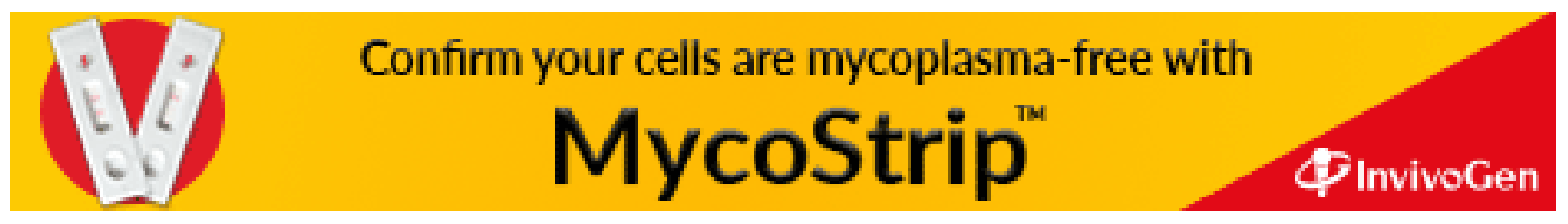

